\title{
Effect of Strategic Alliance Management On the Performance of Microfinance Institutions In Rwanda
}

\author{
Nshimiyimana Charles ${ }^{1}$ \\ PhD Student, Department of Business Management, \\ The Open University of Tanzania, Tanzania \\ Dr. Julius Warren Kule ${ }^{2}$ \\ Senior Lecturer, Department of Business Administration, \\ Faculty of Commerce, University of Eswatine \\ Dr. Saganga Kapaya ${ }^{3}$ \\ Lecturer, Department of Accounting and Finance, \\ Faculty of Business, The Open University of Tanzania, Tanzania \\ DOI: 10.29322/IJSRP.11.05.2021.p11320 \\ http://dx.doi.org/10.29322/IJSRP.11.05.2021.p11320
}

\begin{abstract}
One of the ways to improve performance of MFIs is to encourage them to form strategic alliance. The purpose of this study was to assess the effect of strategic alliance management on the performance of Microfinance Institutions in Rwanda. The target population was 491 MFIs, and a sample size of 220 was determined using Slovene's formula. Primary data for the study was collected by use of structured questionnaire. Structural Equation Modeling (SEM) was used to establish the relationship between strategic alliance management and performance of MFIs. The SEM results revealed that the model was significant $\left(\chi^{2}=\mathbf{2 3 . 5 6}, \mathbf{p}=\mathbf{0 . 0 5 1 8}\right)$ with the overall $\mathrm{R} 2=0.588$. This implied that $58.8 \%$ of the performance of MFIs is influenced by the changes in strategic alliance management. The results have both practical and theoretical implications. Since a positive relationship exists, it is recommended that policy makers as well as managers/CEO in MFIs should promote strategic alliance as a tool for improving the performance of these organizations.
\end{abstract}

Key terms: Strategic alliance management, performance, microfinance, Rwanda

\section{INTRODUCTION}

In this era of globalization and advanced technology, business environment has become increasingly competitive. Firms must be vigilant and use strategic management tools to remain profitable and sustainable. This has led to a considerable attention devoted towards the formation of strategic alliances. From strategic alliances perspectives, organizations can gain tangible resources such as product design and technology or intangible resources such as brand reputation and patents (Kim,2015; Norman, 2017). Strategic alliances also provide benefits to firms, such as economies of scale (market-based alliances) and improvements to long-term competitive advantage (R\&D- and technology-focused alliances).

Importantly, strategic alliances can offer firms differential access to resources, such as distribution channels, marketing skills, financial capital, quality product and service and R\&D knowledge, which in turn influences organization capacity to engage in inter-firm rivalry. They create marketing efficiency and stability which enable firms to reap maximum benefits from such alliances (Ko, et al., 2020). For institutions, strategic alliances represent an important tool to ensure the knowledge advancement and the availability of complementary resources (Lubello et al., 2015).

But a look at many studies on strategic alliance reveals that many researchers studied strategic alliances with emphasis on large enterprises and few studies paid attention to small and medium enterprises (Maher, 2018). Compared to larger enterprises, Microfinance Institutions (MFIs) have more resource restrictions (Hung and Lin, 2015), and they are more in need of deploying strategic alliances to achieve sustainable and effective performance (Chan, 2018). Therefore, according to Kar and Swain (2018), strategic alliances can greatly benefit MFIs to pool new skills and gain resources that help them to relieve poor performance.

These strategic alliances may also play an important role in the development of MFIs in developing countries including African countries, but the scarce literature on the subject creates a lack of information to make this strategy more popular among MFIs in these countries. Furthermore, in the field of strategic alliances, the service industry remain understudied, 
especially the financial service industry (Geleta, 2016). Some empirical studies have demonstrated that the relationships between strategic alliances and business performance are mixed (Rothaermel and Deeds, 2004), such as VendrellnlHerrero et al., (2018) who stated that alliances tend to exhibit high failure rates. This leaves the debate on the effects of strategic alliance on organization performance which is active topic among researchers (Alaaraj, Mohamed \& Bustamam, 2018).

The current study was conducted to investigate the effect of strategic alliance management among MFIs in Rwanda. Its worthy to note that a number of initiatives to boost the microfinance sector in Rwanda have been put in place so far, including the development of a legal and regulatory framework. In additional, the development of a sector policy is underway. Despite the fact that the microfinance sector in Rwanda is still young, it has been growing at a fast pace in the last years and its outreach surpasses that of the traditional banking industry. Briefly, microfinance sector in Rwanda is relatively young (Eularie, 2018).

The history of microfinance in Rwanda can be traced back to the informal mutual help organizations which existed for years, though the sector was formalized in 1975 with the establishment of the first Banque Populaire in Rwanda (Mutual Saving Bank). After 1994, international humanitarian organizations encouraged rapid growth of microfinance as part of wider relief and reconciliation programs. The period during the mid-1990s was characterized by the emergence of new microfinance providers who used various approaches (Rwamigabo, 2019; Eularie, 2018).

This study contributes to the theory because it serves as a proof to see whether strategic alliances contribute positively or negatively to the organization performance in Rwanda's financial service industry and avail empirical literature on strategic alliance field. Further, in the current study, the idea of new model which was developed and validated in Rwanda, originated from Muthoka \& Oduor (2014)'s model which was applied in manufacturing industry in Kenya, due to that reason the tested model in Rwanda in microfinance sector is the novel of this current research. Moreover, there are few existing research on microfinance institutions that have been conducted in advanced countries, developing and African countries, but where Rwanda belongs are almost unsearched (Franco \& Haase 2015; Culpan,2009).

The null hypothesis of the study was formulated as below

$\mathrm{H}_{0}$ : There is no significant effect of strategic alliance management on the performance of Microfinance Institutions in Rwanda.

\section{EMPIRICAL LITERATURE}

\subsection{Theoretical Review}

\subsubsection{Transactional Cost Theory}

The transaction cost theory was proposed by Ronald Coase in 1937. More succinctly transaction costs are: search and knowledge costs, bargaining and decision costs, and policing and enforcement costs. According to transaction cost theory, the firm's decision of mode of transacting is influenced by the minimization of the sum of production and transaction costs (Huda, et al., 2019). The transaction cost theory is considered as the most dominating theory in regards to alliances. Transaction costs exist due to the bounded rationality of actors and opportunism among actors, causing friction on markets (Albers, 2019). Actors will presumably choose the option in the spectrum of 'market and hierarchy' that leads to a minimization of these costs. The term hierarchy in this case refers to actors internalizing functions in the form of firms instead of using the market. While markets and hierarchies are polar opposites, alliances could be seen as something in between the spectrum (Penney \& Combs, 2019).

Yasuda (2018) states that transaction cost theory could be extended to explain alliances, even if it perhaps is not the only viable explanation. Transaction cost model contributes positively to the firm's performance due to the cost-production reduction similar to the resource based theory's idea.

\subsubsection{Strategic Behavioral Theory}

This theory can be traced back to Cyert and March in their work 'a behavioral theory of firm' written in 1963. It refers to actions taken by firms which aim to influence the market environment during which they compete. In reference to this definition, strategic behavior involves primarily long-run actions and decisions like production capacity, research and development (R\&D), investment, location, advertising, product differentiation (Ketprapakorn \& Kantabutra, 2019). The theory has two categories: Non-cooperative behavior occurs when a firm tries to improve its position relative to its rivals by seeking to prevent them from entering a market, driving them out of business or notably reducing their profits as well.

Cooperative behavior occurs when firms during a market seek to coordinate their actions and thus limit their competitive responses. Companies are expected to form cooperative agreements if they believe that the arrangements will better enable them to meet their strategic objectives, with the focus being on maximizing profits (Vogus, 2018). 


\subsubsection{Resource-based theory}

Resource based theory is a theory to achieving competitive advantage that emerged in 1980s and 1990s, after the significant works published by Wernerfelt, B. ("The Resource-Based View of the Firm"), Prahalad and Hamel ("The Core Competence of The Corporation"), Barney, ("Firm resources and sustained competitive advantage") and others. The supporters of this view argue that firms should look inside the institution to seek out the sources of competitive advantage rather than watching competitive environment for it (Arslan, 2018).

The resource based view of the firm has been instrumental for the analysis of strategic alliance formation as there is growing consensus that the rise in the number of strategic alliances has been driven by resource interdependence and complementarities (de Man \& Luvison, 2019). March, Waquet and Martinet (2017) noted that every firm owns a diverse outline of tangible and intangible resources. The RBV establishes the existence of key firm resources that can be used to achieve superior performance. The theory of Resource Based View assumes that individuals are inspired to make maximum use of economic resources available and rational choices that a firm makes which are shaped by economic framework (Dyer, et al., 2020).

Resource Based View has contributed in strategic management through its emphasis on firm-specific resources as bona fide source of high performance. For a firm to have a superior performance, resources and capabilities have to qualify as exceedingly valuable, rare, inimitable, and non-substitutable.

\subsection{Empirical Review}

Dubas et al. (2018) and Mori (2019 stated that microfinance is about banking the unbankable bringing credit, savings and other essential financial services within the reach of tens-or rather hundreds of millions of people who are too poor to be served by regular banks, in most case because they are unable to offer sufficient collateral. Also, Kalra and Mathur (2018) referred microfinance as the provision of credit and other financial services of very small amounts to the poor and small businesses to pursue self-employment or support their small businesses. Microfinance can provide a range of benefits that poor households highly value such as a long-term increase in income and consumption (Dubas et al. 2018). Microfinance enables the poor to develop micro and small enterprises, which enhance their income earning capacity and improve life standard (Mori, 2019: Kamba-Kibatshi, 2018).

According to Wang et al. (2018) alliance is a choice to increase market power, increase political power, increase research, production and marketing or other functions, and provide good product and services. Alliances play a critical role in firm survival, providing the access to critical resources that allow gaining and maintaining competitive advantages in today turbulent economic environment (Cobeña et al., 2017).

According to Keith (2020), the literature on alliance has shifted its main attention to business networking that is realized through alliance. Moreover, the new aspect of alliance focus on clusters and other kind of associations among small firms like MFIs to cause economic process through productivity gains supported alliance. It's clearly argued that the success of commercial sector in Europe is predicated on a system that socializes risk across a broad array of public and personal institutions (Gundolf, Jaouen \& Gast, 2018).

Islam, Hossain and Mia (2018) note that small firms like microfinance institutions don't need to bear the whole burden of developing new technologies, finding new markets or training skilled workers to supply quality products and services. These can be achieved through formation of strategic alliances.

Studies have confirmed that firms which possess heterogeneous alliance portfolios tend to be more innovative and generate better financial performance (Bhawe, \& Zahra, 2019; Degener, Maurer \& Bort, 2018; Hagedoorn, Lokshin, \& Zobel, 2018). On the other hand, some research have shown that diversity in alliance is yet important because it helps the firms to have a wider scope of alliance as well as access to diverse resources. For instance, Chung, Kim \& Kang (2019) note that if alliances cover similar technologies and there is redundancy in the alliance portfolio, performance may be negatively affected, and more cessations observed.

In addition, as the complexity of managing a heterogeneous portfolio of alliances increases, coordination among alliances and effective allocation of resources becomes challenging (Das \& Teng, 2019; de Man \& Luvison, 2019). Management of conflicting demands of multiple and heterogeneous partners as well as monitoring and controlling of the performance of a large-scope portfolio may make alliance activity less effective (Chung, Kim \& Kang, 2019).

According to O'Dwyer and Gilmore (2018), strategic alliance is a purposive relationship between two or more independent firms that involves the exchange, sharing, or co-development of resources or capabilities to achieve mutually relevant benefits. It involves integrating the firm capabilities with another firm as partners in order to create synergy for better performance. Further, Burgelman (2020) defined strategic alliance as a strategic coalition which needs a good partner to 
ISSN 2250-3153

conduct a developing partnership, where organizational resources and capabilities are equitably shared and new ones are acquired and developed.

Similarly, Yuan, et al. (2018), describe strategic alliances as collaborative efforts between two or more firms which pool their resources in an attempt to realize mutually compatible goals that they could not achieve easily alone. Strategic alliance brings about a cooperation among partners looking to share their resources soon mutually improve their performance either through learning and knowledge sharing, or through creating opportunities to create competiveness. Furthermore, strategic alliance has to contribute to the successful implementation of the strategic plan; therefore, the alliance must be strategic in nature. The relationship has got to be supported by executive leadership and formed by lower management at the highest step macro level. While the subsequent doesn't represent a comprehensive definition for a strategic alliance, at this stage, one might define a strategic alliance as a relationship between organizations for the purposes of achieving successful implementation of a strategic plan (Gundolf, Jaouen \& Gast, 2018).

According to some researchers, the success of any single alliance depends on some key factors that are relevant at each stage of alliance evolution (Degener, Maurer \& Bort, 2018). These include (a) the formation phase, wherein a firm deciding to initiate an alliance selects an appropriate partner, (b) the design phase, wherein a firm (and its partner) set up appropriate governance to oversee the alliance, and (c) the post formation phase, wherein a firm manages the alliance on an ongoing basis to realize value (Haghighi \& Jalali, 2018; Xia, et al., 2018).

Keith (2020) investigated how to make alliance count through creating innovation for spearheading growth in the company. The results of the study indicated that strategic alliances facilitate the growth of companies though gained access to foreign market and increase organization performance through experience and knowledge. The author concluded that the basic conditions in entering the strategic alliance, methods of forming alliances, types of alliances and elements of alliances.

Ko, et al. (2020) carried out a research on the effects of strategic alliance emphasis and marketing efficiency on firm value under different technological environments. The research was based on data from 337 alliances from 1994 to 2014 . Of these alliances, 177 involved computer equipment companies and 160 involved food companies. The results showed that market efficiency create no value in a high-tech industry and that there exists a negative effect of market efficiency on firm value in low-tech industry. In addition, the type of strategic alliance does not have statistical influence on firm value. Kim (2016) conducted a study on the effect of strategic alliance types such as joint venture, technical alliance, joint technical development and joint marketing on firm productivity in South Korea. The study employed a two-stage-leastsquares method and found that joint ventures positively affect firm performance and that the formation of international intra-industry alliances has a positive impact on firm performance.

Hung and Lin (2015) conducted a study to investigate how competitive priorities relate to organization performance, with the inclusion of strategic alliances; its mediating effect is examined for MFIs in Taiwan. The study used SEM as data analysis tool. The study results showed that quality and flexibility priorities can improve organization performance. Cost priority can influence the management of strategic alliances. Strategic alliances directly influence firm performance. Through the full mediating effect of strategic alliances, cost priority enables a positive impact on organization performance.

Muthoka and Oduor (2014) investigated the effects of Strategic Alliances on Organizational Performance: Supermarkets and their Alliances in Kenya. The study employed a multiple regression model to analyze data and the study findings showed that strategic alliances positively and significantly affect supermarket performance. The study results indicated that technological strategic alliances have no significant impact on the levels of performance of a firm. They also indicated that there was a weak, negative effect on production strategic alliances and performance, for the supermarkets while for supermarket alliances there was a large, positive effect on the two variables. There was a strong, positive effect on marketing strategic alliances and performance for the supermarkets. In general, the results indicated that strategic alliances had a strong relationship with supermarket performance.

Correspondingly, Muange and Maru (2015) conducted a study within the aim of determining the effect of strategic alliances on firm performance and the moderating effect of firm size in retail organizations in Nairobi County in Kenya. The study findings indicated that joint marketing alliances, procurement-supplier alliances, joint manufacturing alliances, and technology development alliances have the importance and positive effect on organization performance.

Therefore, their findings also showed that a joint marketing, procurement-supplier, joint manufacturing, and technology development alliances mostly enhance organization performance. Additionally, the authors concluded that strategic alliance helps firms to improving productivity, production efficiency, and profitability. It also helps within the availability 
of products to the last users. Finally, it also enables the firms to participate more in corporate social responsibility projects which in turn successively improves the quality of living of the communities around them.

In order for strategic alliances to be successful, there should exist a particular level of cooperation between alliance partners. According to Albers (2019), cooperation in an alliance is a joint performance of different partners within a given setting and involves actors, activity and mode of operation. In this cooperation, there exists a relationship during which individuals, groups and organizations interact through the sharing of complementary capabilities and resources, or leveraging these for the aim of mutual benefit. Therefore, we could view cooperation as a necessary element in strategic alliance strategy which features a pre-condition that needs two or more parties' involvement supported exchange or sharing of complementary resources or skills.

Degener, Maurer and Bort (2018) state that working alongside other organizations in an alliance, might encourage the transfer of knowledge, leading to the creation of resources that might rather be difficult to mobilize and develop. Cooperation gives rise to many gains for the firm which include the division of cost of latest product development and services between the firms that are working together, shortened lead times also as contribution of core competences by the various partners involved (Burkhardt, 2018).

It's therefore necessary to thoroughly analyze potential partners, because the choice of partner may affect the benefit that firms can gain from the alliance (Degener, Maurer \& Bort, 2018).Wang et al. (2018) argue that alliance success is influenced mainly by smart partner selection.

In order to achieve a wining strategic alliance, partners should select a strategy that 'fit' their motive can lead to desirable results. The main target is on the word "fit" which according to Baaij and Reinmoeller (2018) refers to whether the partners involved in the alliance have selected the best alliance type driving towards the motive that drives them. Burgelman (2020) further described the strategic fit as a means of ensuring a winning strategy that matches the underlying motives of the partners in the alliance. Moreover, de Man and Luvison (2019) stressed that forming great strategic fit may be a prerequisite for any alliance success. At the same time, Gundolf et al. (2018) noted that the partners in an alliance should both possess ambitious motive that would consequently drive the alliance to meet the organizational goals intended in such cooperation.

\subsection{Organization Performance}

The concept of organizational performance is predicated upon the thought that a corporation may be a voluntary association of productive contributions, including human, physical, and capital resource, for the aim of achieving a shared purpose. Those providing the assets will only commit them to the organization so long they are satisfied with the worth they receive in exchange, relative to alternative uses of the assets (Arena, Azzone \& Bengo, 2018).

According to Hagedoorn et al., (2018), organizational performance is the degree to which an organization achieves its goals, the degree an organization acquires the needed resources, the degree an organization maintains internal harmony, and the degree an organization satisfies it stakeholders. However, Prashantham \& Yip, 2019 highlighted a number of difficulties evident in the measurement of organizational performance. First, the future performance may be a reflection of past performance, secondly, the organization performance can be reversed over time due to feedback mechanisms, and third, that differences exist between short-term and long-term influences on organizational performance. There is evidence suggesting that an organization forming alliances will enhance its organizational performance (Nielsen, 2017).

According to Lebans \& Euske (2016) firm performance is a set of financial and non-financial indicators which offer information on the degree of achievement of objectives and results. In this study, the organizational perfor mance has been measured using a three-item scale: profitability, return on assets (ROA), and sales growth. Furthermore, available literature shows the use of these indicators to measure changes in knowledge, competencies, and learning of organizations. Shrader (2016) has adopted sales growth; Goerzen\& Beamish (2015), ROA; and Dussauge, Garrette, \& Mitchell, (2017), increase in market share. Therefore, the averages of the three indicators which are the observable variables serve to gauge the firm performance.

Richard (2018) study was very creative study. It goes beyond mere examination of direct relationship between strategic management and organizational performance. During this study enterprise performance has been measured in terms of employing a three - item scale: profitability, return on assets (ROA), and sales growth. Furthermore, available literature shows the utilization of those indicators to live changes in knowledge, competencies, and learning of organizations .

\subsection{Conceptual Framework}




\section{Independent Variable}

\begin{tabular}{|l|l|l|}
\hline $\begin{array}{l}\text { Strategic Alliance } \\
\text { Management }\end{array}$ & Firm Performance \\
\cline { 2 - 3 } & & \\
\hline
\end{tabular}

A conceptual framework is a tool used to guide the inquiry; it is a set of ideas used to structure the research, a sort of a map (Kothari et al., 2012). It is therefore, the researcher's own position on the problem and gives the direction to the study. The concepts under study in this research were the strategic alliance management as the independent variable and firm performance as the dependent variable. Strategic management alliance was measured on a seven-point Likert scale using six different statements. The firm performance was measured using return $\mathrm{n}$ assets, sales and profitability.

\section{Research Methodology}

\subsection{Study population and Sampling}

The study conducted a survey on microfinance institutions in Rwanda. The research considered all of the five provinces of Rwanda. As it is indicated in the report of the Ministry of Finance and Economic Planning of August $2013^{1}$, 416 SACCOs (microfinance at 3 level) and 75 MFIs were registered, and this makes a total of 491 which was the research population for this study. Slovene's sampling formula (Rosenstein, 2019) was used to determine the sample size

Where:

$$
n=\frac{N}{1+N e^{2}}=\frac{419}{1+419 * 0.05^{2}} \approx 220
$$

$\mathrm{n}=$ Sample size

$\mathrm{N}=$ total population $=491$

$\mathrm{e}=$ Level of confidence or error margin $=0.05$

The researcher used random sampling method to give equal opportunity to all MFIs in the population.

\subsection{Variables measurement procedures}

Primary data was obtained using a structured questionnaire made of seven-point Likert scale where $1=$ strongly disagree, $2=$ disagree, 3 more/less disagree, $4=$ undecided, $5=$ more/less agree, $6=$ agree and $7=$ strongly disagree. This was used to measure the independent variable strategic alliance management. Firm performance is measured as the average of the Return on Assets (ROA), Return on Sales (ROS) and profitability. The respondents who included the managers/CEOs of the selected MFIs helped in providing these ratios.

\subsubsection{Data processing and analysis}

The study used quantitative method and Structural Equation Modeling for data analysis. I have preferred to use SEM because of it is a popular method across discipline and increasingly is a 'must' for researchers in the so cial sciences (Ling \& Ling, 2017) and many other studies in strategic alliances have also used SEM, Plazibat and Davor (2013), Jabar, Othman, and Idris (2011). It is a combination of factor analysis and regression or path analysis (Boateng, 2018). The popularity of SEM is based on its role in testing complete theories and concepts.

However, before building the model, preliminary model analyses were conducted to allow the data and the model to meet the assumptions for SEM. The basic assumptions for a standard SEM model include, sample size, interval scale for data, multivariate normality distribution, model identification, and uncorrelated error terms. The procedure involved four basic steps that were followed. Step one involved building the path diagram in the SEM builder interface. In this, the measurement model and the structural model were drawn as a path diagram connecting latent variables and the observed variables. Step two involved testing the reliability and validity of the measurement model. The reliability of the model was tested using Cronbach's alpha test for reliability.

The third step involved model estimation. The Maximum Likelihood (ML) method was used because there were no missing variables in the data. The last step involved examining the results and drawing up conclusion. Different statistical measures were used to help draw the conclusions on model fit and on the hypothesis. The model was specified as below: performance $=\beta_{0}+\beta_{1} *$ sma $+\epsilon$

Where $\beta_{0}=$ constant

1 National Microfinance Policy Implementation Strategy 2013-2017, A Roadmap to Financial Inclusion (https://www.bnr.rw/index.php?id=250) 


$$
\begin{aligned}
& \beta_{1}=\text { regression coefficient } \\
& \text { sma }=\text { strategic management alliance } \\
& \epsilon=\text { error term }
\end{aligned}
$$

\section{Results and Discussions}

\subsection{Respondents' Characteristics}

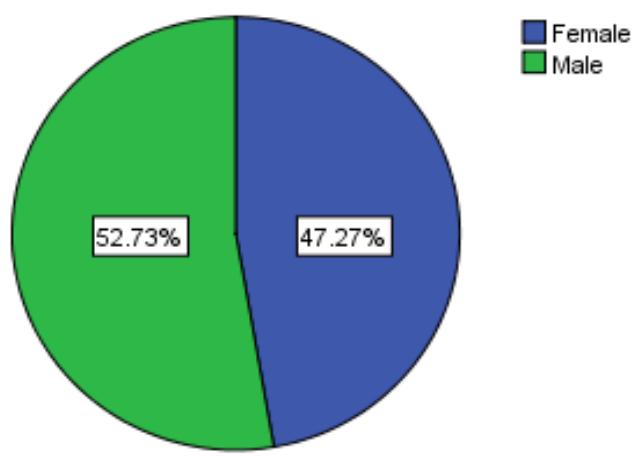

Figure 1: Gender of the respondents (Source: Researcher, 2020)

According to Figure 1, shows that $47.27 \%$ of the respondents were female and $53.73 \%$ were male. Although, there is a little difference of $6 \%$ percentage, generally these results indicate that the sample was reasonably represented in terms of gender.

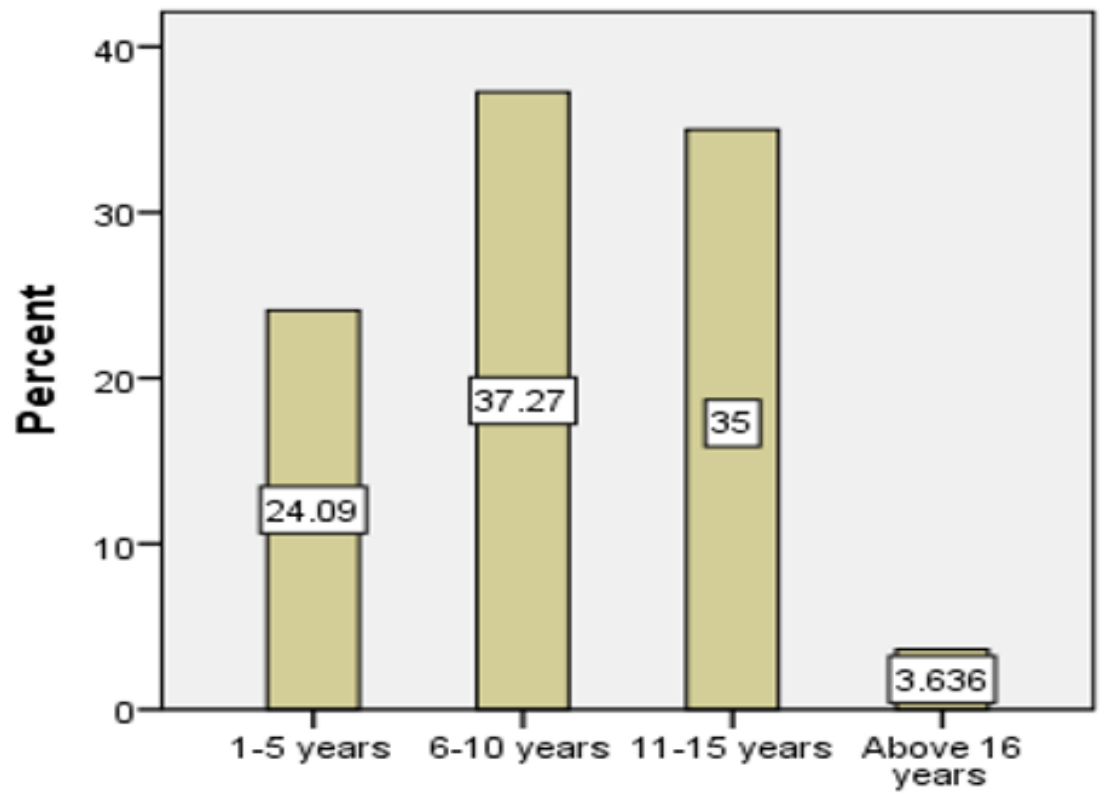

Figure 2: Working experience of respondents (Source: Researcher, 2020)

Figure 2 shows that $24.09 \%$ of respondents had less than 5years of work experience, $37.27 \%$ had between 6 and 10 years of experience, and $3.64 \%$ had above of 15 years of work experience.

Table 1: Respondents' level of education

\begin{tabular}{|l|l|l|l|}
\hline Education level & Frequency $\mathbf{( N = 2 2 0 )}$ & Percentage & Cumulative percentage \\
\hline Secondary level & 102 & 40.45 & 40.45 \\
\hline Bachelor level & 102 & 46.36 & 86.82 \\
\hline Masters level & 29 & 13.18 & 100.00 \\
\hline
\end{tabular}

(Source: Researcher, 2020)

Table 1 shows that $40 / 45 \%$ of respondents were of secondary/high school level, followed by bachelor level $46.36 \%$ and masters level $13.18 \%$. These results suggest the majority of respondents, who were CEOs and managers of microfinance and SACCOs, had attained the university level.

Table 2: Institutions age

\begin{tabular}{|l|l|l|l|}
\hline MFI age & Frequency $\mathbf{N}=\mathbf{2 2 0}$ & Percentage & Cumulative percentage \\
\hline
\end{tabular}




\begin{tabular}{|l|l|l|l|} 
& & & \\
\hline Under 5 & 33 & 15.00 & 15.00 \\
\hline Between 6 and 10 & 101 & 45.91 & 60.91 \\
\hline Between 11 and 15 & 67 & 30.45 & 91.36 \\
\hline Between 16 and 20 & 16 & 7.27 & 98.64 \\
\hline Above 21 & 3 & 1.36 & 100.00 \\
\hline Total & 220 & 100.00 & 100.00 \\
\hline
\end{tabular}

(Source: Researcher, 2020)

Table 2 shows that $15 \%$ of visited MFI were under five old. $45.91 \%$ were between six and ten years old, $30.45 \%$ were 7 between sixteen and twenty years and $1.36 \%$ were above 21 years old. As outlined above the initiative of establishing microfinance started in 2000s. This is the reason behind having the majority of institutional between six and ten years old. As outlined above the initiative of establishing microfinance started in $2000 \mathrm{~s}$. This is the reason behind having the majority of institutional between six and ten years old.

Table 3: Institutions size

\begin{tabular}{|l|l|l|l|}
\hline Number of employees & Frequency $(\mathbf{N = 2 2 0})$ & Percentage & Cumulative percentage \\
\hline under 50 & 8 & 3.64 & 3.64 \\
\hline Between 51 and 100 & 67 & 30.45 & 34.09 \\
\hline Between 101 and 150 & 75 & 34.09 & 68.18 \\
\hline Between 151 and 200 & 42 & 19.09 & 87.27 \\
\hline Above 201 & 28 & 12.73 & 100.00 \\
\hline Total & 220 & 100.00 & \\
\hline
\end{tabular}

(Source: Researcher, 2020)

The institution size is based by the number of employees. Table 3 shows the majority of visited MFI (34.09 \%) had between 101 and 150 number of employees. The table also shows that only $3.64 \%$ of visited institutions had under 50 percentage of employees. Cumulatively, $68.18 \%$ of the firms were having below 150 employees. As expected, these institutions fall under microfinance.

\subsection{Descriptive Statistics}

The analysis of inferential data preceded the analysis of descriptive data. Mean, Standard Deviation (SD), Variance, Skewness and Kurtosis. The descriptive statistics for all the constructs are shown in Table 4.

Table 4: Descriptive Statistics

\begin{tabular}{lcccrr}
\hline Variables & Obs & Mean & Stdev. & Skewness & Kurtosis \\
\hline StratMgt1 & 220 & 5.186 & 1.546 & -.514 & 2.158 \\
StratMgt2 & 220 & 5.195 & 1.425 & -.338 & 2.085 \\
StratMgt3 & 220 & 5.386 & 1.355 & -.537 & 2.553 \\
StratMgt4 & 220 & 5.686 & 1.173 & -.648 & 2.704 \\
StratMgt5 & 220 & 5.682 & 1.076 & -.509 & 2.799 \\
StratMgt6 & 220 & 5.609 & 1.187 & -.589 & 2.678 \\
Performance & 220 & 3.928 & .7 & -.307 & 2.362 \\
\hline
\end{tabular}

Table 4 presents the descriptive statistics for the study variables which include the number of observations, mean, 
standard deviation, skewness and kurtosis. According to Paolella (2018), the acceptable range for skewness is between -3 and +3 while for skewness is between -10 and +10 whenever using the SEM technique. This showed that the values obtained in this research were within the acceptable threshold in terms of skewness and kurtosis.

\subsection{Model Analysis}

This research used the structural equation modeling technique to achieve the research objectives. However, before building the model, preliminary model analyses were conducted to allow the data and the model to meet the assumptions for SEM. The basic assumptions for a standard SEM model include, sample size, interval scale for data, multivariate normality distribution, model identification, and uncorrelated error terms. The assumption on sample size holds that the sample should be large enough, at least more than 200 , for structural equation modeling.

This research was able to meet this requirement with a sample size of 220 observations. Similarly the data is require d to have interval scale. According to Jackson (2015), if Likert scale is symmetric and equidistance, it can sufficiently approximate an interval scale. The use of Likert scale with seven items enabled the researcher to meet this requirement. Similarly, the errors terms are assumed to be uncorrelated since the data is not time series nor related to time. The test for multivariate normality was conducted using Doornik-Hansen test which revealed significance $\left(\chi^{2}=149.736, p<0.05\right)$.

According to Biswas, Giri \& Srivastava, (2006), for a model to achieve identification, the number of distinct sample moments should be greater than or equal to the number of distinct parameters to be estimated (which gives the degrees of freedom, d.f.). If they are equal, the model is considered to be just identified. If the number of distinct sample moments is less than the number of distinct parameters to be estimated, then the model is unidentified. However if greater than, then it is over identified. In this case, looking at the output of the estimation, the model was over identified since d.f. were computed in each estimation.

According to Schermelleh-Engel, Moosbrugger and Müller (2003) estimations in SEM can only be done if the model is just identified or over identified. Further, note that there exists no specific statistics to ensure that a structural equation model fits. They specifically recommend that the researcher should keep checking results against the $\chi^{2}$ results which provide the level of significance and an idea of whether the model fits the empirical data. In addition, other goodness of fit statistics exists that can be used. With this knowledge, the researcher was able to proceed with the analysis.

\subsubsection{Measurement model: validity and reliability}

As recommended by Hooper, Coughlan and Mullen (2008), before any structural equation modeling is conducted, the measurement model should be tested for reliability of the observable constructs. This was done using the Cronbach alpha reliability test presented in Table 5 .

Table 5: Cronbach alpha Reliability test.

\begin{tabular}{|c|c|c|c|c|c|c|}
\hline & & & & & & \\
\hline & & & & & average & \\
\hline & & & item-test & item-rest & interitem & \\
\hline Item & Obs & Sign & correlation & correlation & covariance & alpha \\
\hline StratMgt1 & 220 & + & 0.388 & 0.244 & 0.218 & 0.705 \\
\hline StratMgt2 & 220 & + & 0.493 & 0.373 & 0.208 & 0.691 \\
\hline StratMgt3 & 220 & + & 0.454 & 0.336 & 0.213 & 0.695 \\
\hline StratMgt4 & 220 & + & 0.282 & 0.168 & 0.230 & 0.710 \\
\hline StratMgt5 & 220 & + & 0.306 & 0.203 & 0.229 & 0.707 \\
\hline StratMgt6 & 220 & + & 0.215 & 0.098 & 0.236 & 0.716 \\
\hline
\end{tabular}


(Source: Researcher, 2020)

The cut point for reliability is an alpha equal to or greater than 0.7 (Esposito, et al., 2010). According to Table 5, the lowest alpha is 0.691 which is close to the cutoff point and therefore retained. In fact the overall test scale was 0.704 which approximate to the cut point provided enough reliability to retain the measurement scale and all the items.

\section{Findings on the Research Hypothesis}

The study sought to examine the effect of strategic alliance management on the Microfinance Institutions' performance. The null hypothesis for this objective was formulated as follows:

$\mathrm{H}_{0}$ : There is no significant effect of strategic alliance management on the performance of MFIs.

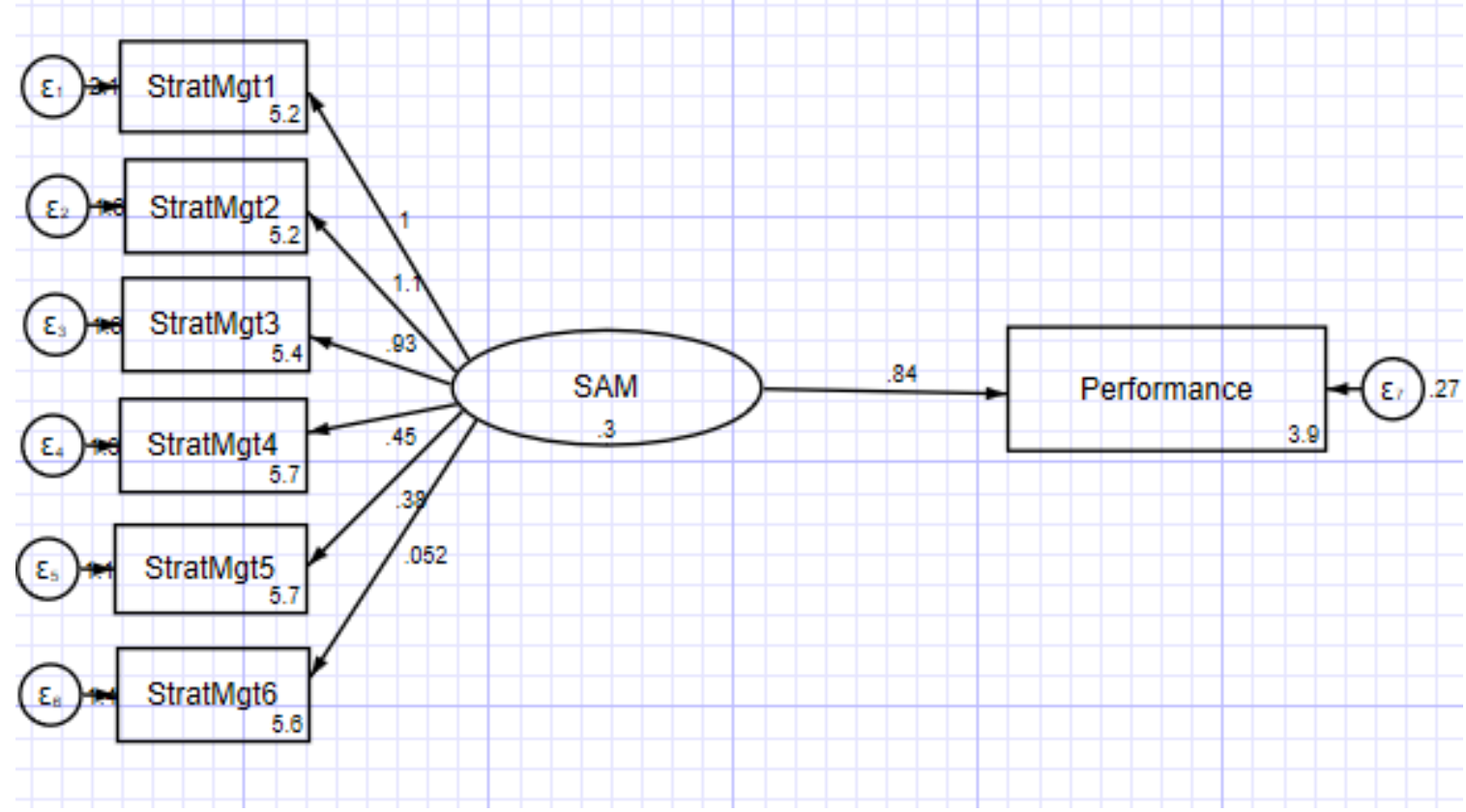

SAM=Strategic Alliance Management (Source: Researcher, 2020)

\section{Figure 3: SEM diagram for the path analysis}

Figure 3 shows the result for the path analysis using SEM. The measurement model was made up of the strategic alliance management which was measured using the StratMgt1, StratMgt2, StratMgt3, StratMgt4, StratMgt5 and StratMgt6 representing the six question items formulated in the questionnaire. As shown in the figure, the path coefficient from strategic alliance management to performance is 0.84 . This is also shown in Table 6 with a p-value of 0.002 implying that the coefficient is significant at $5 \%$.

Table 6: Model Estimation

OIM

\begin{tabular}{|c|c|c|c|c|c|c|}
\hline & Coef. & Std.Err. & $\mathrm{Z}$ & $\mathrm{P}>\mathrm{Z}$ & [95\%Conf. & Interval] \\
\hline \multicolumn{7}{|c|}{ Measurement } \\
\hline \multicolumn{7}{|c|}{ StratMgt1 } \\
\hline SAM & \multicolumn{3}{|c|}{1} & \multicolumn{2}{|c|}{ (constrained) } & \\
\hline _cons & 5.186 & 0.104 & 49.880 & 0.000 & 4.983 & 5.390 \\
\hline \multicolumn{7}{|c|}{ StratMgt2 } \\
\hline SAM & 1.129 & 0.397 & 2.850 & 0.004 & 0.352 & 1.907 \\
\hline _cons & 5.195 & 0.096 & 54.210 & 0.000 & 5.008 & 5.383 \\
\hline \multicolumn{7}{|c|}{ StratMgt3 } \\
\hline SAM & 0.930 & 0.300 & 3.100 & 0.002 & 0.342 & 1.518 \\
\hline _cons & 5.386 & 0.091 & 59.090 & 0.000 & 5.208 & 5.565 \\
\hline \multicolumn{7}{|c|}{ StratMgt4 } \\
\hline SAM & 0.454 & 0.235 & 1.930 & 0.053 & -0.006 & 0.914 \\
\hline
\end{tabular}




\begin{tabular}{|c|c|c|c|c|c|c|}
\hline _cons & 5.686 & 0.079 & 72.060 & 0.000 & 5.532 & 5.841 \\
\hline \multicolumn{7}{|l|}{ StratMgt5 } \\
\hline SAM & 0.381 & 0.198 & 1.920 & 0.055 & -0.008 & 0.770 \\
\hline _cons & 5.682 & 0.072 & 78.470 & 0.000 & 5.540 & 5.824 \\
\hline \multicolumn{7}{|l|}{ StratMgt6 } \\
\hline SAM & 0.052 & 0.201 & 0.260 & 0.798 & -0.343 & 0.446 \\
\hline _cons & 5.609 & 0.080 & 70.270 & 0.000 & 5.453 & 5.766 \\
\hline \multicolumn{7}{|l|}{ Performance } \\
\hline SAM & 0.841 & 0.274 & 3.070 & 0.002 & 0.304 & 1.378 \\
\hline _cons & 3.928 & 0.047 & 83.430 & 0.000 & 3.836 & 4.021 \\
\hline var(e.StratMgt1) & 2.076 & 0.227 & & & 1.676 & 2.572 \\
\hline var(e.StratMgt2) & 1.635 & 0.192 & & & 1.298 & 2.058 \\
\hline var(e.StratMgt3) & 1.566 & 0.184 & & & 1.245 & 1.971 \\
\hline var(e.StratMgt4) & 1.307 & 0.130 & & & 1.077 & 1.588 \\
\hline var(e.StratMgt5) & 1.109 & 0.109 & & & 0.915 & 1.345 \\
\hline var(e.StratMgt6) & 1.401 & 0.134 & & & 1.162 & 1.689 \\
\hline var(e.Performance & 0.274 & 0.068 & & & 0.169 & 0.444 \\
\hline \multicolumn{7}{|l|}{ ) } \\
\hline $\operatorname{var}(\mathrm{SAM})$ & 0.303 & 0.157 & & & 0.110 & 0.835 \\
\hline
\end{tabular}

LR test of model vs. saturated: chi2 $(14)=23.56$, Prob $>$ chi2 $=0.0518$ (Source: Researcher, 2020)

Table 6 shows the outcome of the structural equation modeling in more details. As shown in the table, the model was found to be significant at $5 \%$ with p-value at acceptable levels of 0.0518 .

Table 7: Goodness of fit test

\begin{tabular}{c|rrr|rrr}
\hline & \multicolumn{3}{|c|}{ Variance } & & & \\
depvars & fitted & predicted & residual & R-squared & mc2 \\
\hline observed & & & & & & \\
StratMgt1 & 2.378886 & .3027282 & 2.076157 & .1272563 & .35673 & .1272563 \\
StratMgt2 & 2.020868 & .3862098 & 1.634658 & .1911109 & .4371623 & .1911109 \\
StratMgt3 & 1.827989 & .2616511 & 1.566338 & .143136 & .3783332 & .143136 \\
StratMgt4 & 1.369811 & .0623885 & 1.307422 & .0455453 & .2134135 & .0455453 \\
StratMgt5 & 1.153304 & .0440314 & 1.109272 & .0381785 & .1953931 & .0381785 \\
StratMgt6 & 1.401736 & .0008041 & 1.400932 & .0005736 & .0239506 & .0005736 \\
Performance & .4877571 & .2141469 & .2736102 & .439044 & .662604 & .439044 \\
\hline & & & & & & \\
\hline
\end{tabular}

$\mathrm{mc}=$ correlation between depvar and its prediction

mc2 $=m^{\wedge} 2$ is the Bentler-Raykov squared multiple correlation coefficient

(Source: Researcher, 2020)

Table 7 shows the results for the goodness of fit at equation level. The overall $\mathrm{R}^{2}$ was found to be 0.588 which implied that $58.8 \%$ of the performance of MFIs can be explained by strategic alliance management. 


\section{Conclusion}

The results showed that in general strategic alliance contribute positively to the microfinance's performance compared to the organizations without alliance. The findings also showed that organizations can benefit in terms of resources when they engage in alliances. It is recommended that the government should encourage healthy strategic alliance even in other service organizations as way of improving their performance, and grow country's economy. The government could protect and create conducive environment in term of national policies and regulations. The study further recommends that business competitors embrace strategies that can enhance market efficiency, rather than bringing market frictions and imperfections. One of such strategies is through healthy strategic alliances.

\section{References}

Albers, S. (2019). The Design of Alliance Governance Systems. Wiesbaden, Germany: Springer, Gabler.

Anatan, L. (2018). An institutional perspective of knowledge transfer within university and industry alliance. International Journal of Economic Policy in Emerging Economies, 11(4), 378-395.

Anderson, J. C., Håkansson, H., \& Johanson, J. (2017). Dyadic business relationships within a business network context. Journal of marketing, 58(4), 1-15.

Arena, M., Azzone, G., \& Bengo, I. (2018). Performance measurement for social enterprises. VOLUNTAS: International Journal of Voluntary and Nonprofit Organizations, 26(2), 649-672.

Arslan, B. (2018). The interplay of competitive and cooperative behavior and differential benefits in alliances. Strategic Management Journal, 39(12), 3222-3246.

Baaij, M., \& Reinmoeller, P. (2018). Prelims', Mapping a Winning Strategy: Developing and Executing a Successful Strategy in Turbulent Markets. UK: Emerald Publishers

Bhawe, N., \& Zahra, S. A. (2019). Inducing heterogeneity in local entrepreneurial ecosystems: the role of MNEs. Small Business Economics, 52(2), 437-454.

Boateng, S. (2018). Structural Equation Modelling (SEM) Made Easy for Business and Social Science Research Using SPSS and Amos. Sage Publisher.

Burgelman, R. A. (2020). Strategy is destiny: How strategy-making shapes a company's future. USA: Free Press.

Burkhardt, K. (2018). Private Equity Firms: Their Role in the Formation of Strategic Alliances. John Wiley \& Sons.

Burkholder, G. J., Cox, K. A., Crawford, L. M., \& Hitchcock, J. H. (Eds.). (2019). Research design and methods: An applied guide for the scholar-practitioner. SAGE Publications, Incorporated.

Cainelli, G., Ganau, R., \& Iacobucci, D. (2016). Do Geographic Concentration and Vertically Related Variety Foster Firm Productivity? Micro-Evidence from Italy. Growth and Change, 47(2), 197-217.

Calantone, R. J., Cavusgil, S. T., \& Zhao, Y. (2015). Learning orientation, firm innovation capability, and firm performance. Industrial marketing management, 31(6), 515-524.

Cannella Jr, A. A., \& Monroe, M. J. (2018). Contrasting perspectives on strategic leaders: Toward a more realistic view of top managers. Journal of management, 23(3), 213-237.

Carayannopoulos, S., \& Auster, ER (2015). External knowledge sourcing in biotechnology through acquisition versus alliance: A KBV approach. Research Policy, 39 (2), 254-267.

Caserta, M., Monteleone, S., \& Reito, F. (2018). The trade-off between profitability and outreach in microfinance. Economic Modelling, 72, 31-41.

Challapalli, P., Vadapalani, C., Dineshwar, A., \& Bajaj Finance Ltd, C. (2019). Microfinance, a Strategic Tool for Financial Inclusion. Mehr Chand Mahajan DAV College for Women, 51.

Chan, S. K. L. (2018). Hierarchical microcredit networks. International Journal of Sociology and Social Policy.

Chandra, R.D. (2018). Microfinance and Its Impact on Entrepreneurial Development Sustainability and inclusive growth. USA: IGI Global.

Chatterjee, S., DuttaGupta, S., \& Upadhyay, P. (2018). Sustainability of microenterprises: an empirical analysis. Benchmarking: An International Journal.

Cheng, CC, \& Krumwiede, D. (2018). Enhancing the performance of supplier involvement in new product development: the enabling roles of social media and firm capabilities. Supply Chain Management: An International Journal. Vol.23(3), 12-34.

Chung, D., Kim, M. J., \& Kang, J. (2019). Influence of alliance portfolio diversity on innovation performance: the role of internal capabilities of value creation. Review of Managerial Science, 13(5), 1093-1120.

Colm, L., Ordanini, A., \& Parasuraman, A. (2017). When service customers do not consume in isolation: a typology of customer copresence influence modes (CCIMs). Journal of Service Research, 20(3), 223-239.

Cozza, C., Malerba, F., Mancusi, M. L., Perani, G., \& Vezzulli, A. (2012). Innovation, profitability and growth in medium and high-tech manufacturing industries: evidence from Italy. Applied Economics, 44(15), 1963-1976. 
ISSN 2250-3153

Cui, A. S., \& O'Connor, G. (2018). Alliance portfolio resource diversity and firm innovation. Journal of Marketing, 76(4), 24-43.

Danneels, E., \& Kleinschmidtb, E. J. (2018). Product innovativeness from the firm's perspective: Its dimensions and their relation with project selection and performance. Journal of Product Innovation Management: An International Publication of the Product Development \& Management Association, 18(6), 357-373.

Das \& Teng, 2019

Das, T. K., \& Teng, B. S. (2019). Managing risks in strategic alliances. Managing Interpartner Risks in Strategic Alliances, 165.

De Faria, P., \& Mendonça, J. (2018). Innovation strategy by firms: do innovative firms grow more?. International Journal of Entrepreneurship and Small Business, 12(2), 173-184.

de Man, A. P., \& Luvison, D. (2019). Collaborative business models: Aligning and operationalizing alliances. Business Horizons, 62(4), 473-482.

Degener, P., Maurer, I., \& Bort, S. (2018). Alliance portfolio diversity and innovation: The interplay of portfolio coordination capability and proactive partner selection capability. Journal of Management Studies, 55(8), 13861422.

Dupas, P., Karlan, D., Robinson, J., \& Ubfal, D. (2018). Banking the Unbanked? Evidence from three countries. American Economic Journal: Applied Economics, 10(2), 257-97.

Dussauge, P., Garrette, B., \& Mitchell, W. (2017). Learning from competing partners: Outcomes and durations of scale and link alliances in Europe, North America and Asia. Strategic management journal, 21(2), 99-126.

Dyer, J. H., Singh, H., \& Hesterly, W. S. (2018). The relational view revisited: A dynamic perspective on value creation and value capture. Strategic Management Journal, 39(12), 3140-3162.

Eularie, M. (2018). Agricultural Financing and Microfinance Industry in Rwanda: Growth, Trends and Challenges. International Journal of Social and Economic Research, 8(2), 117-132.

Geleta, E. B. (2016). The Microfinance Mirage: The Politics of Poverty, Social Capital and Women's Empowerment in Ethiopia. Routledge.

Goerzen, A., \& Beamish, P. W. (2015). The effect of alliance network diversity on multinational enterprise performance. Strategic management journal, 26(4), 333-354.

Gundolf, K., Jaouen, A., \& Gast, J. (2018). Motives for strategic alliances in cultural and creative industries. Creativity and Innovation Management, 27(2), 148-160.

Hagedoorn, J., \& Duysters, G. (2018). External sources of innovative capabilities: the preferences for strategic alliances or mergers and acquisitions. Journal of management studies, 39(2), 167-188.

Hagedoorn, J., Lokshin, B., \& Zobel, A. K. (2018). Partner type diversity in alliance portfolios: Multiple dimensions, boundary conditions and firm innovation performance. Journal of Management Studies, 55(5), 809-836.

Haghighi, M., \& Jalali, S. H. (2018). Strategic Alliance Formation from the Institutional Theory Perspective.

Huda, M., Qodriah, S. L., Rismayadi, B., Hananto, A., Kardiyati, E. N., Ruskam, A., \& Nasir, B. M. (2019). Towards cooperative with competitive alliance: Insights into performance value in social entrepreneurship. In Creating business value and competitive advantage with social entrepreneurship (pp. 294-317). IGI Global.

Islam, M., Hossain, A. T., \& Mia, L. (2018). Role of strategic alliance and innovation on organizational sustainability. Benchmarking: An International Journal.

Kalra, V., \& Mathur, H. P. (2018). Evaluation of Microfinance Institutions in Varanasi with Special Reference to Client Education. Cambridge Scholars Publishing.

Keith, L. J. D. (2020). Making History Together: How to Create Innovative Strategic Alliances to fuel the growth of your Company. Florida Hospital Publishing.

Ko, W. L., Kim, S. Y., Lee, J. H., \& Song, T. H. (2020). The effects of strategic alliance emphasis and marketing efficiency on firm value under different technological environments. Journal of Business Research.

Ling, L., \& Ling, P. (2017). Emerging Methods and paradigms in education research. Teaching and Learning, $2021,299$.

Maher, C. (Ed.). (2018). Handbook of Research on Value Creation for Small and Micro Social Enterprises. USA: IGI Global.

Mori, M. (2019). Banking Underserved Market Segments. Open Journal of Social Sciences, 7(03), 506.

Nielsen, B. B. (2017). Determining international strategic alliance performance: A multidimensional approach. International Business Review, 16(3), 337-361.

O'Dwyer, M., \& Gilmore, A. (2018). Value and alliance capability and the formation of strategic alliances in SMEs: The impact of customer orientation and resource optimisation. Journal of Business Research, 87, 58-68. 
Prashantham, S., \& Yip, G. (2019). Local Firms within global value chains: From local assembler to value partner. In The Oxford Handbook of Management in Emerging Markets. Oxford University Press New York.

Rosenstein, L. D. (2019). Research Design and Analysis: A Primer for the Non-statistician. John Wiley \& Sons.

Rwamigabo, E. R. (2019). Challenges and Opportunities of Micro or Small Social Enterprises in Rwanda. In Handbook of Research on Value Creation for Small and Micro Social Enterprises (pp. 254-270). IGI Global.

Shrader, C. (2016). Collaboration and performance in foreign markets, the case of young high technology manufacturing firms. Academy of Management Journal, 44(3), 45-60.

Vogus, T. J. (2018). What is it about relationships? A behavioral theory of social capital and performance. Members-only Library.

Wang, C. N., Nguyen, X. T., Le, T. D., \& Hsueh, M. H. (2018). A partner selection approach for strategic alliance in the global aerospace and defense industry. Journal of Air Transport Management, 69, 190-204.

Xia, J., Wang, Y., Lin, Y., Yang, H., \& Li, S. (2018). Alliance formation in the midst of market and network: Insights from resource dependence and network perspectives. Journal of Management, 44(5), 1899-1925.

Yasuda, H. (2018). Governance Mechanisms of Inter-organizational Relationship: Comparative Analysis of Three Forms of Alliance Governance. Journal of Strategic Management Studies, 10(1), 81-93. 